\title{
Specification, design and performance of the generator for vertical axis wind turbines of the deep wind project
}

\author{
Leban, Krisztina; Ritchie, Ewen; Schmidt Paulsen, Uwe
}

Published in:

Proceedings of the Technologies and material for renewable energy, environment and sustainability (TMREES19)

Link to article, DOI:

10.1063/1.5117051

Publication date:

2019

Document Version

Publisher's PDF, also known as Version of record

Link back to DTU Orbit

Citation (APA):

Leban, K., Ritchie, E., \& Schmidt Paulsen, U. (2019). Specification, design and performance of the generator for vertical axis wind turbines of the deep wind project. In Proceedings of the Technologies and material for renewable energy, environment and sustainability (TMREES19) (1 ed., Vol. 2123). [030020] AIP Conference Proceedings Vol. 2123 https://doi.org/10.1063/1.5117051

\section{General rights}

Copyright and moral rights for the publications made accessible in the public portal are retained by the authors and/or other copyright owners and it is a condition of accessing publications that users recognise and abide by the legal requirements associated with these rights.

- Users may download and print one copy of any publication from the public portal for the purpose of private study or research.

- You may not further distribute the material or use it for any profit-making activity or commercial gain

- You may freely distribute the URL identifying the publication in the public portal 


\section{Specification, design and performance of the generator for vertical axis wind turbines of the deep wind project}

Cite as: AIP Conference Proceedings 2123, 030020 (2019); https://doi.org/10.1063/1.5117051

Published Online: 17 July 2019

Krisztina Leban, Ewen Ritchie, and Uwe Schmidt Paulsen

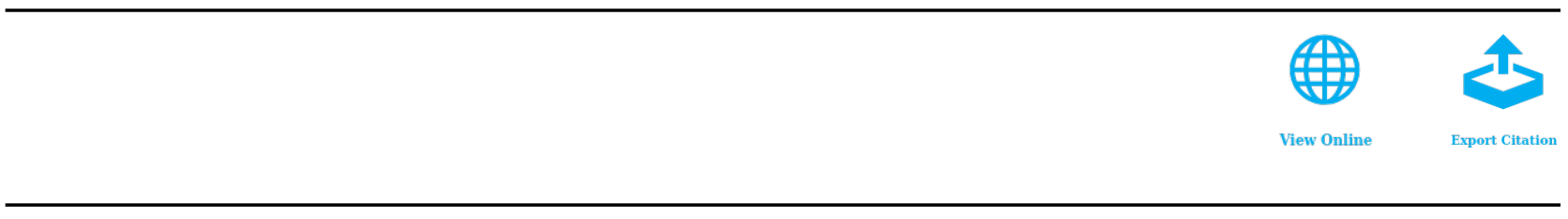

\section{Conference Proceedings}

Get $30 \%$ off all print proceedings!

\section{Enter Promotion Code PDF30 at checkout}

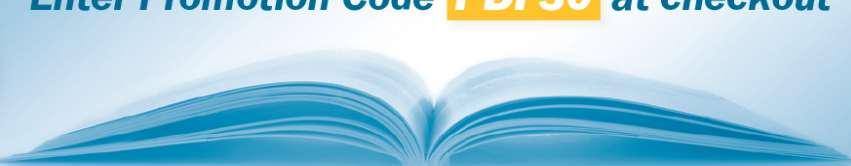




\title{
Specification, Design and Performance of the Generator for vertical axis wind turbines of the Deep Wind project
}

\author{
Krisztina Leban ${ }^{1}$, Ewen Ritchie ${ }^{1}$, Uwe Schmidt Paulsen²,a) \\ ${ }^{1}$ Department of Energy Technology, Aalborg University, Pontoppidanstrcede 111, 9220 Aalborg Denmark \\ ${ }^{2}$ Department of Wind Energy, DTU Campus Risø, Frederiksborgvej 399, 4000 Roskilde Denmark \\ a)uwpa@dtu.dk
}

\begin{abstract}
The generator of the DeepWind Vertical Axis Wind Turbine (VAWT) concept is reviewed, discussing special challenges, detailing the function specification, briefly presenting the design tool, some results, the proposed construction and aspects of the generator performance.
\end{abstract}

\section{INTRODUCTION}

DeepWind is a vertical-axis wind turbine (VAWT) concept with the turbine rotor mounted on a floating spar buoy and with the generator at the bottom, Figure 1 [1]. The conceptual design and project outcomes offer novelty and take advantage of the water, using it as a very large bearing, but with the technical challenges of placing the generator at the underwater position [2]. The challenges are to design a high reliability, easily maintainable generator mounted up to $300 \mathrm{~m}$ below sea level. The Darrieus wind turbine must be started by using the generator as a motor, braked normally and abnormally, and held stationary by the generator. For the $5 \& 20 \mathrm{MW}$ versions, $3 * 13.5 \mathrm{kV}$ was proposed with lower voltages for the smaller versions. Generated voltage will be reduced proportionately for lower operating speeds. DeepWind work includes design of the functional parts of the generator. Remaining challenges are: how to handle the seawater; mechanical design for low cost and maintainability [3].

To avoid the use of an oil-filled gearbox, a direct drive generator was selected, requiring high torque at low speed. A $1 \mathrm{~kW}$ demonstrator version was built [6], and tested in Roskilde Fjord and in a wave tank at MARIN (Maritime Research Institute, Wageningen, Netherlands). A second demonstrator of $0.5 \mathrm{MW}$ for installation at an exposed offshore site is projected, and $5 \& 20 \mathrm{MW}$ full size commercial machines are envisaged. This paper introduces that part of the DeepWind project where the generator was specified and a design tool was produced and validated, and designs were proposed.

\section{SPECIAL CHALLENGES ASSOCIATED WITH THE DEEPWIND VAWT SYSTEM}

The task of designing a low cost DeepWind system seems easy as first impressions of the concept offer a simple design with few components. However, basic challenges exist: the turbine operates at variable speed and needs overspeed protection; the generator environment is deep under the sea water, the 2-bladed rotor generates a twice per revolution load cycle with potential risks of edgewise instabilities that may transmit dynamic loads to the generator [5], potential excessive tower fatigue [6], and unproven procedures and handling for installation and maintenance of underwater parts.

Technical solutions to some of these specific challenges are already known from the submarine industry, underwater mining business and offshore oil and gas industry, and have inspired specific solutions for DeepWind. Other challenges include the need for high system efficiency, and that the Cost Of Energy, (COE) can compete with current technology. For the generator the materials use of rare-earth-element metals (e.g. Neodymium and Dysprosium) may represent a cost function constraint. Mitigating conditions are that the long and slender spar buoy may help by absorbing some of the rotor torque pulsations, and that fewer bearings are needed to support the turbine

Technologies and Materials for Renewable Energy, Environment and Sustainability AIP Conf. Proc. 2123, 030020-1-030020-12; https://doi.org/10.1063/1.5117051 Published by AIP Publishing. 978-0-7354-1863-9/\$30.00 
[1]. A special challenge is that all forces, torques and bending moments arising from the action of the wind and water and from the generator itself, must be transmitted to the mooring system through the construction of the generator, which adds extra constraints to the design of the generator housing. Direct drive was recommended to avoid pollution problems associated with lubricant leakage. This in turn leads to a very large diameter of the generator that demands a correspondingly large mass of material to support it.

\section{FUNCTION SPECIFICATION OF THE GENERATOR}

The specification is intended to provoke consideration of all aspects of the DeepWind Generator, in all anticipated situations. Where possible the specifications are quantified using information provided by the project consortium, or from outside sources. The specification is subdivided into two main parts, namely Normal operation, covering all aspects of the operation of the DeepWind generator when the generator is driven by the wind turbine and is supplying load to the grid via the converter, and Abnormal operation, covering all other situations that occur at irregular intervals and apply for a short time only, such as starting, stopping and fault conditions.

\section{Normal operation}

Normal operation is when the generator is acting as a generator driven by the wind turbine and loaded by the grid via the power electronics converter.

\section{Power}

The power available for generation will be a function of the wind speed and was originally presented by L. Vita in [1], see Fig. 2. The output power to the grid will be reduced by the losses in the generator, the power converter and the power transmission line. It is evident from Fig. 2, for the $5 \mathrm{MW}$ version, that the available driving power is a complicated function of the wind speed. Assuming a normal operating range of wind speed from $4 \mathrm{~m} / \mathrm{s}$ to $15 \mathrm{~m} / \mathrm{s}$, the corresponding range of shaft input power will be $0.2 \mathrm{MW}$ to $5.0 \mathrm{MW}$, with the $5.0 \mathrm{MW}$ corresponding to a wind speed of $14 \mathrm{~m} / \mathrm{s}$. For wind speeds greater than $14 \mathrm{~m} / \mathrm{s}$ the power will be reduced to around $3.75 \mathrm{MW}$.

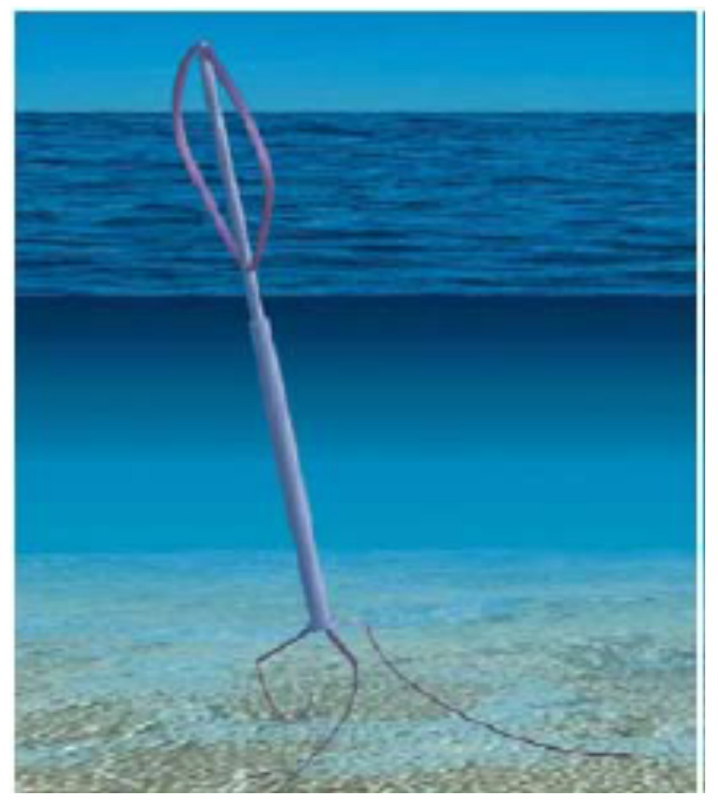

FIGURE 1. Preliminary Illustration of the DeepWind concept [1]

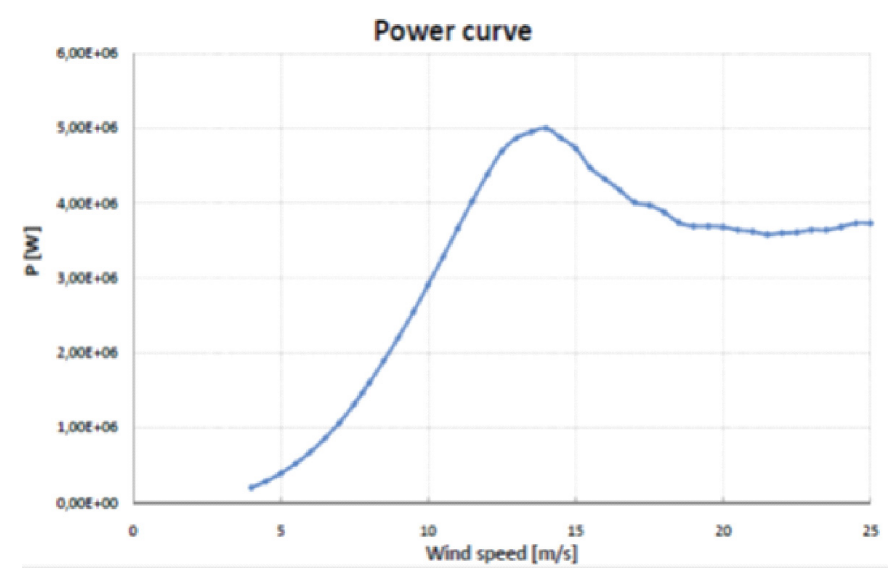

FIGURE 2. Shaft input power to the $5 \mathrm{MW}$ generator (original version) $[1]$ 


\section{Shaft Speed}

The shaft speed is very low and variable. For a $5 \mathrm{MW}$ generator, the shaft speed corresponding to a wind speed of $4 \mathrm{~m} / \mathrm{s}$ is $2.71 \mathrm{rpm}$ and for all wind speeds greater than $7.76 \mathrm{~m} / \mathrm{s}$ is $5.26 \mathrm{rpm}$. The shaft speed is correspondingly higher for a $0.5 \mathrm{MW}$ demonstrator (max. $27 \mathrm{rpm}$ ), and lower for the $20 \mathrm{MW}$ version. The speed for the $20 \mathrm{MW}$ VAWT was still under discussion as there are conflicting arguments for selecting different speeds. This will be discussed later in this paper.

\section{Torque}

The torque is an input from the shaft corresponding to the product of the power and the speed. The operating torque range is from $0.702 \mathrm{MNm}$, corresponding to a wind speed of $4 \mathrm{~m} / \mathrm{s}$, to $9.08 \mathrm{MNm}$ corresponding to a wind speed of $14 \mathrm{~m} / \mathrm{s}$. From $14 \mathrm{~m} / \mathrm{s}$ and above the torque is reduced, as the blades have stalled. When the turbine rotor reaches a speed of $5.26 \mathrm{rpm}$, corresponding to a wind speed of $7.76 \mathrm{~m} / \mathrm{s}$, the torque is $2.66 \mathrm{MNm}$. The shaft speed now remains constant while the torque increases to $9.08 \mathrm{MNm}$, corresponding to $14 \mathrm{~m} / \mathrm{s}$. For wind speeds exceeding $14 \mathrm{~m} / \mathrm{s}$, the torque falls to around $6.7 \mathrm{MNm}$. A summary of the input shaft characteristics is given in Table 1 . An equal reaction torque must be applied at the generator stator and is transmitted via the mooring system to the sea bed.

An interesting aspect is that because the VAWT is fitted with two blades, the torque provided by the wind will be cyclic as the blades rotate, with two cycles per revolution. Due to the long flexible shaft, this will be a dynamic situation that must be analyzed carefully to avoid dangerous oscillation levels, causing instability and fatigue of the shaft and moorings.

TABLE 1. Rated power, torque, and shaft speed for various versions of DeepWind generator

\begin{tabular}{llrrrr}
\hline Attribute & Unit & $\mathbf{1 ~ k W}$ & $\mathbf{5 0 0} \mathbf{~ k W}$ & $\mathbf{5 M W}$ & $\mathbf{2 0 M W}$ \\
\hline Shaft Input Power & $\mathrm{kW}$ & 1.58 & 550 & 5000 & 22500 \\
Shaft speed & $\mathrm{rpm}$ & 430 & $20-27$ & 5.262 & $5(1)$ \\
Rated Input torque & $\mathrm{Nm}$ & 35 & $239-177 \cdot 10^{3}$ & $18 \cdot 10^{6}$ & $43(215) \cdot 10^{6}$ \\
\hline
\end{tabular}

\section{Frequency}

The frequency is directly proportional to the shaft speed. So for a $5 \mathrm{MW}$ generator the range will be $1.94: 1$, the same as the speed range. The exact values of frequency are fixed by the number of poles selected, as the type of machine selected is a synchronous machine. 314 poles were proposed, meaning that the maximum nominal frequency at $5.3 \mathrm{rpm}$ will be $13.8 \mathrm{~Hz}$. The number of poles and the nominal frequency will be the subject of simultaneous engineering, as this affects the dimensions of the turbine and generator and also the lifetime of the generator full power converter.

\section{Voltage}

Selection of the voltage is governed by the ability of the insulation to withstand the electric field under the prevailing conditions. Secondary considerations are the ohmic loss of power and voltage in the transmission to the grid. A third consideration is the rated voltage of the power devices of the power converter. This affects the reliability of the architecture of the power electronic bridge needed to control the power. If the voltage is such that the current is very large, requiring a topology with several devices in parallel, if one device fails, then the system can continue operating at reduced power. On the other hand, if the voltage is so high that several series connected devices are required, should one device in the series chain fail, the whole phase leg will be lost, thus closing down the system. Engineering samples of Silicon Carbide devices rated at $15 \mathrm{kV}$ are currently being life-tested and devices rated at 20 $\mathrm{kV}$ are projected.

The proposed maximum nominal voltage for the $5 \mathrm{MW}$ version is $13.5 \mathrm{kV}$. This would require a medium voltage insulation system, as opposed to the industrial voltage insulation system normally applied for $690 \mathrm{~V}$ generators, Fig. 6. This requires careful consideration, as it causes the slots to have increased cross-section, [7] and ultimately in this extreme case, increased diameter of the generator.

If the magnetic field were to be excited by current flowing in the rotor winding then some change in its magnitude would be possible to compensate for operating conditions. This will manipulate the voltage at a given speed. 
Manipulation will be possible within limits, to control the maximum available torque and power, and to optimize the operating efficiency.

\section{Current}

For 5MW, some $4.2 \mathrm{kA}$ would be required for a line voltage of $690 \mathrm{~V}$. This would require the generator to be wound with conductors some $30[\mathrm{~mm}]$ square, assuming a current density of $5 \mathrm{~A} / \mathrm{mm}^{2}$. With 4 parallel circuits, the conductors would be $15[\mathrm{~mm}]$ square. This is very thick wire to manipulate and would require open slots to enable pre-formed coils to be laid in them. This is a manufacturing technique that is commonly used with medium voltage windings, making it attractive to select a medium voltage winding. At $13.5 \mathrm{kV}$, the full load current of the $5 \mathrm{MW}$ generator would be around $214 \mathrm{~A}$ and require wire $6.5 \mathrm{~mm}$ square, providing much easier manipulation.

\section{Temperature Rise}

The materials used for insulating the windings from earth and from each other determine the maximum allowable temperature of the winding conductor material. This is to prevent premature deterioration of the insulation materials that are in close contact with the winding conductor. In many cases, cooling of the conductor is by conductive heat transfer through the insulation material.

It is usual to specify the allowable temperature rise of the winding conductors. The allowable temperature rise of the windings is related to the ambient temperature. Normally the maximum ambient temperature for continuous operation is defined to be $40{ }^{\circ} \mathrm{C}$. For the Deep Wind application, the ambient temperature will be that of the surrounding sea, approximately $4{ }^{\circ} \mathrm{C}$. In this case, the allowable temperature rise will be increased.

A class $\mathrm{H}$ system of insulation materials is recommended, meaning that the allowed temperature rise on a full load temperature test in a seawater ambient of $4{ }^{\circ} \mathrm{C}$ will be $155 \mathrm{~K}$, measured by the resistance method.

\section{Ambient Temperature}

As the DeepWind generator system will be located at the bottom of the floater, between $100 \& 200 \mathrm{~m}$ below the surface of the sea, the ambient temperature will be fairly constant, at about $+4{ }^{\circ} \mathrm{C}$.

\section{Enclosure}

Options are available. The enclosure of the generator could be designed to be totally enclosed and watertight, or totally open and filled with sea water. When the seawater outside the generator is $100 \mathrm{~m}$ deep, the pressure will be about 11 bar. At $200 \mathrm{~m}$, the ambient pressure will be about 21 bar. If the casing is watertight the entry of the shaft to the bearing system will have to withstand the pressure, whilst rotating, and at standstill. This also applies to the casing itself.

If the totally enclosed option is chosen some way must be found to keep the seawater out of the generator. The easiest way to make the enclosure capable of withstanding the outside water pressure is to ensure the same pressure inside the enclosure as outside. The question then arises as to which pressurised fluid would be filled inside the generator. This would be the subject of a materials science and biological report that is not part of this project. The fluid chosen should be compatible both with the generator materials and with sea water.

If the open enclosure were chosen, the generator would then be filled with sea water. Some properties of seawater are given and discussed in [8]. It will be necessary to evaluate the consequences of close contact with seawater on all materials used. It should be borne in mind that seawater is not merely a chemical composition, but that it also contains living organisms. The effect on these may be manifold; it will be important that the presence of our machine does not adversely affect the local life; it will also be important that the local life does not impair the efficient function and reliability of the machine (wind turbine and generator). This would be the subject of a materials science and biological report which will be the subject of further study.

A major, challenging function of the enclosure is to transmit all loads, be they forces, bending moments or torques, from the floater to the mooring system. This is a challenging requirement as all of these are very large, and the generator requires precision of centering and roundness, it also contributes to the forces counteracting these but is itself a very weak structure. 


\begin{abstract}
Abnormal operation
Abnormal operation covers all situations that occur only irregularly in the lifetime of the DeepWind generator and apply for a short time only at any one occurrence.
\end{abstract}

\title{
Starting The VAWT
}

When the DeepWind VAWT is required to start, it cannot do this is alone. In this case, the generator will be operated as a motor, via the power converter, and will accelerate the wind turbine to a speed where the turbine is able to provide the driving torque, when the generator will apply zero torque during the remaining acceleration until the required operation speed, corresponding to the actual wind speed, is reached. The starting process should be under controlled torque to provide the starting rates required. This should be arranged so that the dimensions of the converter and generator are no more than that required for normal load. Care must be taken not to exceed the safe working load of every component of the construction.

The available starting power will be limited by the combination of the grid, the transmission line, converter and generator. During the starting period the applied torque is controllable by controlling the power converter. The torque will be absorbed by accelerating the total moment of inertia of the rotating system and any frictional losses in the generator and bearing, and in the tower and turbine rotor system. The mooring system will provide the reaction torque.

The blade designers and the tower/floater designers should determine the maximum allowable torque. Based on this and the available starting power the acceleration rate will be determined. Any critical speeds and resonances that may occur during acceleration should be determined for all proposed constructions as a part of the system design process. Suitable action should be agreed to minimise the effects of the critical speeds and resonances arising during acceleration.

A permanent magnet machine is recommended to reduce losses and avoid the complication of providing excitation current. During startup, the generated back EMF will be proportional to the shaft speed, passing through the origin at zero speed. This is because the magnetic field is in principle constant. This will not be precisely true, as current flowing in the armature (stator) winding will cause a reaction in the magnetic field. In general, the current will be a function of the required torque at any speed.

During starting, the current flowing may be greater than the full load current. This will cause a second order increase of the losses in the winding. The temperature rise will be a dynamic process, dependent on the thermal capacity of the generator, the ability to dissipate the losses, and the time interval during which the losses are applied. Extensive multi physics modelling will be required to determine the temperature of the machine components under these conditions. As for normal operation, the ambient temperature of the seawater is expected to be around $4{ }^{\circ} \mathrm{C}$.

\section{Stopping The VAWT}

For normal, scheduled stopping of the wind VAWT the turbine rotor should be decelerated from operating speed to standstill at an agreed rate. The generator will continue to operate as a generator during rotation. Excess generating torque will be applied to overcome the driving torque from the wind and dissipate the kinetic energy stored in the rotating system. The available braking power will be limited by the combination of the grid, the transmission line, converter and generator. However, the braking process should give high torque at high speed to balance the power being converted from the wind and with some excess to dissipate the stored kinetic energy. During braking, the terminal voltage will be in the same range as that when generating.

\section{Emergency Stopping When The Grid Connection Is Lost}

If the grid connection is lost there will be no load on the generator, but the VAWT may continue to supply power to the shaft. The torque balance will be lost and the VAWT will accelerate. It will be necessary to stop the VAWT. This may be achieved by connecting Dump Resistors as shown in Fig. 3, and dissipating energy in these.

It will be difficult to operate a disc brake or other mechanical brake under water reliably, so a highly reliable electric braking system using the generator should be ensured. 


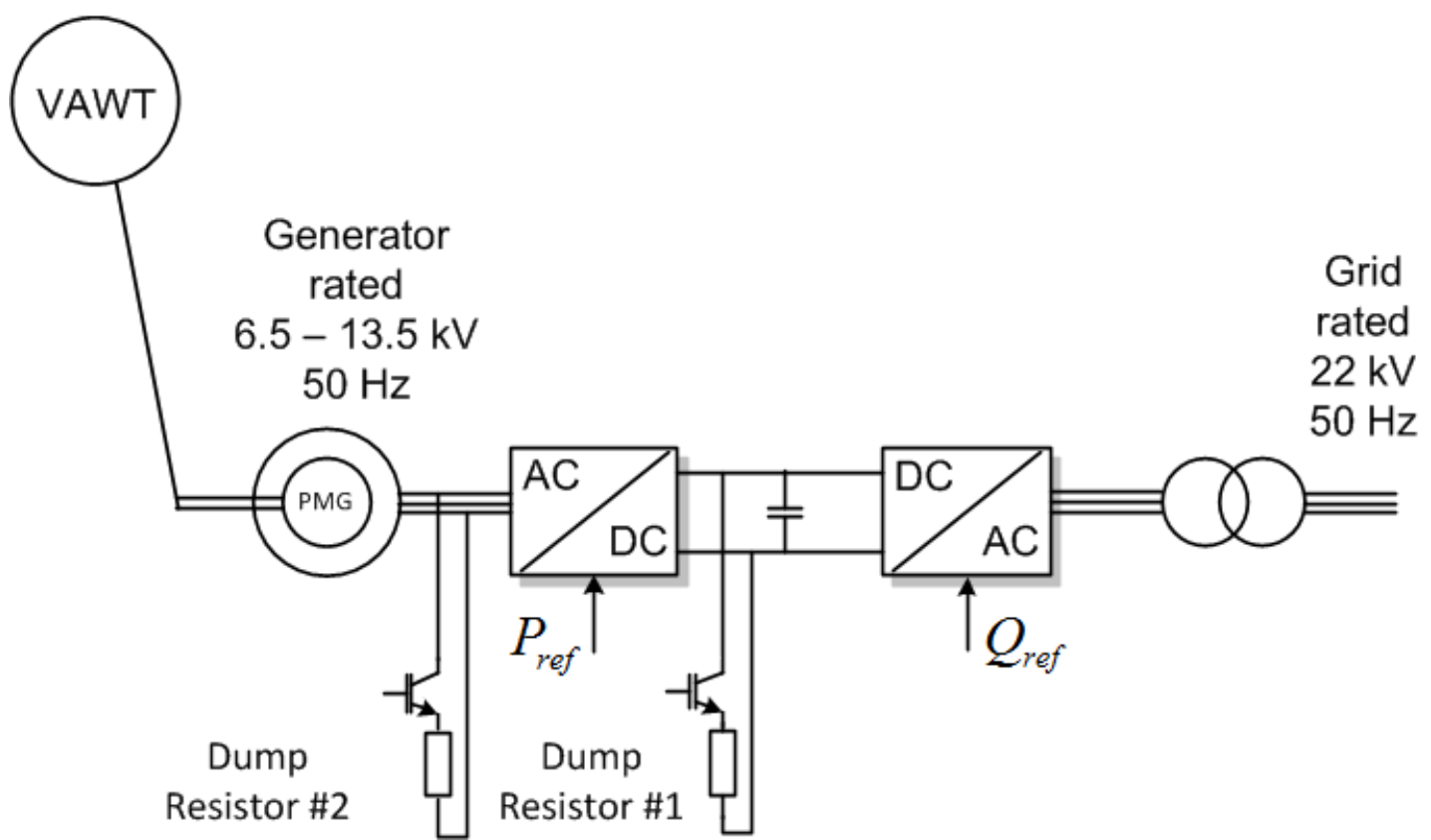

FIGURE 3. Diagram showing the driveline proposed for DeepWind VAWT systems. The Dump resistors are connected only during emergency braking

\section{Holding Torque At Standstill}

The generator is required to provide sufficient torque to prevent rotation during maintenance operations on the turbine and mechanical components. As long as the grid connection is present, the generator will be able to provide holding torque by controlling the speed to be zero.

\section{DESIGN TOOL AND SOME RESULTS OBTAINED}

To enable studies of the effects of selecting different options, a design tool was created for the generator [9]. Fig. 4 shows the data flow and interconnection of the tool. Inputs and design rules are used to create an initial data set. Inputs are free choice variables such as rated power, speed, voltage and frequency and design rules are related to the limits set by the properties of chosen materials. Outputs are values of dimensions, external characteristics and performance that may be displayed as a table of identified numbers or in graphical form. The available variations in this version of the design tool are shown in Fig. 5. The main data set interacts with Vector Fields Opera, an electromagnetic finite element analysis program, Solid Works CAD, and a Matlab/Simulink dynamic model, by automatically writing appropriate input files that can add the dimension values to previously implemented models. Similarly, an input file is written for an optimization program using optionally a genetic algorithm (GA), or a particle swarm optimization (PSO), algorithm. The tool was validated against a small laboratory model and results reported in the literature [9]. The dynamic model was used in connection with dynamic models for the remainder of the system, to enable future studies of system performance. 


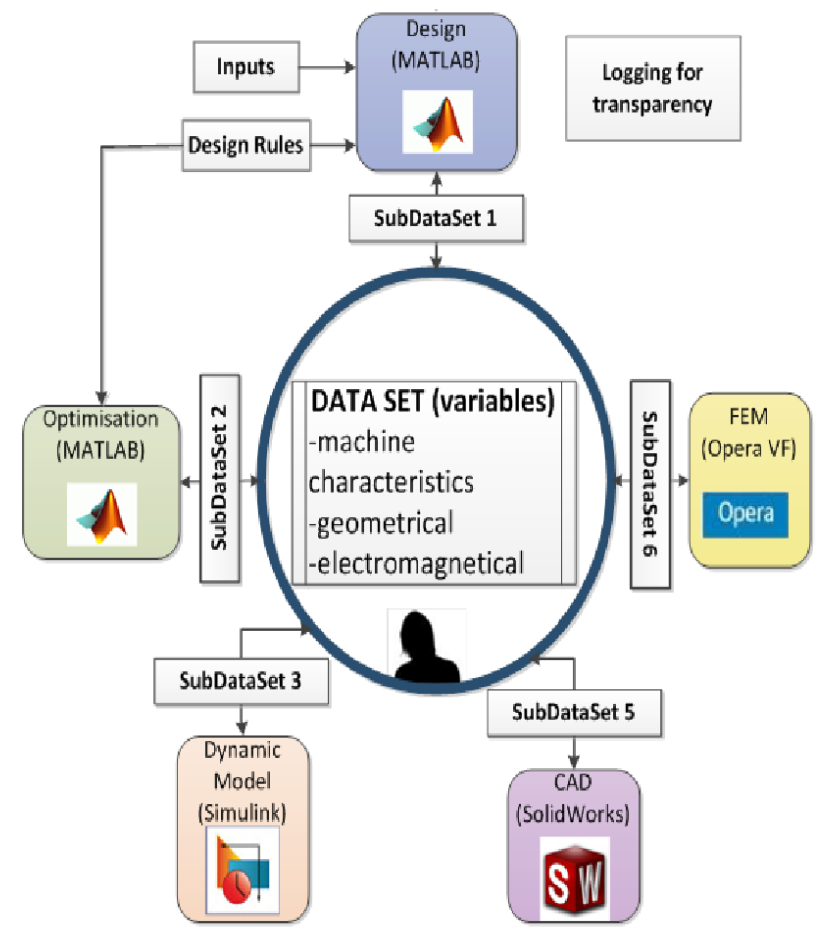

FIGURE 4. Diagram showing the data flow for the generator design tool [9].

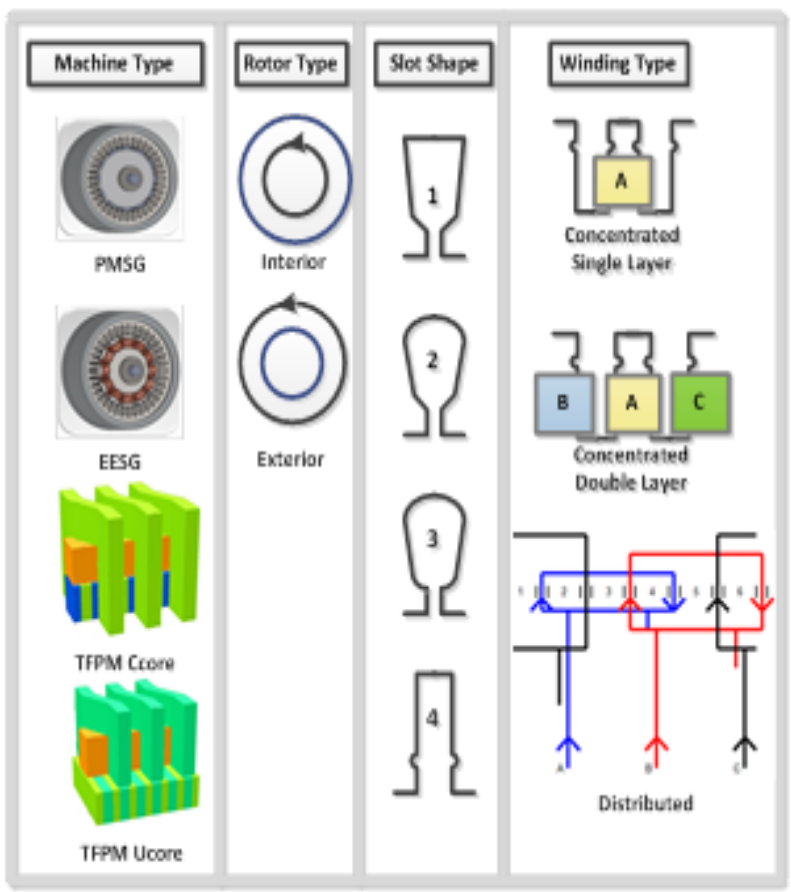

FIGURE 5. Diagram showing available variations in the Generator design tool [9]

Using results from the design tool many different versions of generator were studied, these included radial flux machines and transverse flux machines, with the rotor inside the stator and outside [10,11]. Radial flux machines with two concentric air-gaps and two stators were also studied. An example of some of the output from the design tool is given in Table 2, comparing results from an initial design and optimization runs using each of the two methods implemented. 
TABLE 2. Generator Parameters - Classic Radial flux PM Optimization method

\begin{tabular}{|c|c|c|c|c|c|c|c|c|c|}
\hline Variable & None & PSO & GA & units & Variable & None & PSO & GA & units \\
\hline \multicolumn{5}{|l|}{ Input } & \multicolumn{5}{|l|}{ Output } \\
\hline Shaft power & 6 & 6.24 & 6.24 & MW & $\begin{array}{l}\text { Apparent } \\
\text { power }\end{array}$ & 6 & 6.3 & 6.1 & MVA \\
\hline VAWT torque & 10 & 10 & 10 & $\mathrm{MNm}$ & Real power & 5.7 & 6 & 5.8 & MW \\
\hline \multirow[t]{3}{*}{ Shaft speed } & 5.26 & 5.26 & 5.26 & $\mathrm{rpm}$ & Reactive power & 1.9 & 1.89 & 1.89 & MVA \\
\hline & & & & & Line voltage & 13.5 & 13.5 & 13.5 & $\mathrm{kV}$ \\
\hline & & & & & $\begin{array}{l}\text { Coil, phase, } \\
\text { line Current }\end{array}$ & 259 & 259 & 259 & A \\
\hline \multicolumn{5}{|l|}{ Main dimensions } & \multicolumn{5}{|l|}{ Inner dimensions } \\
\hline Stator outer diameter & 6.145 & 6.561 & 6 & $\mathrm{~m}$ & $\begin{array}{l}\text { Number of } \\
\text { stator slots }\end{array}$ & 339 & 339 & 399 & - \\
\hline Stator bore diameter & 6 & 6.41 & 6.41 & $\mathrm{~m}$ & $\begin{array}{l}\text { Stator slot } \\
\text { width }\end{array}$ & 26 & 27.34 & 28.2 & $\mathrm{~mm}$ \\
\hline Rotor outer diameter & 5.988 & 6.4 & 5.88 & $\mathrm{~m}$ & $\begin{array}{l}\text { Stator slot } \\
\text { height }\end{array}$ & 51 & 48.69 & 51 & $\mathrm{~mm}$ \\
\hline Rotor inner diameter & 5.884 & 6.288 & 5.79 & $\mathrm{~m}$ & Tooth width & 29 & 32 & 26.8 & $\mathrm{~mm}$ \\
\hline Air gap & 6 & 6.414 & 5.8 & $\mathrm{~mm}$ & & & & & \\
\hline Core length & 4.142 & 3.227 & 3.86 & $\mathrm{~m}$ & & & & & \\
\hline \multicolumn{5}{|l|}{ Winding } & \multicolumn{4}{|c|}{ Permanent Magnets NdFeB } & \\
\hline number of poles & 314 & 314 & 314 & - & $\begin{array}{l}\text { number of } \\
\text { poles }\end{array}$ & 314 & 314 & 314 & - \\
\hline number of stator coils & 339 & 339 & 339 & - & B remanent & 1 & 1 & 1 & $\mathrm{~T}$ \\
\hline Turns per coil & 8 & 9 & 8 & - & B working & 0.8 & 0.848 & 0.842 & $\mathrm{~T}$ \\
\hline $\begin{array}{l}\text { Slots per Pole per } \\
\text { Phase }\end{array}$ & 0.36 & 0.36 & 0.36 & - & H working & -220 & -220 & -220 & $\mathrm{~A} / \mathrm{m}$ \\
\hline $\begin{array}{l}\text { Coils in Series per } \\
\text { Phase }\end{array}$ & 113 & 113 & 133 & - & width of PM & 51 & 54.54 & 50.1 & $\mathrm{~mm}$ \\
\hline Coil sides per slot & 2 & 2 & 2 & - & height of PM & 20 & 22.11 & 19.8 & $\mathrm{~mm}$ \\
\hline \multicolumn{5}{|l|}{ Stator core } & \multicolumn{4}{|c|}{ Applied Base cost of materials } & \\
\hline $\begin{array}{l}\text { B max. allowed in } \\
\text { iron }\end{array}$ & 1.7 & 1.7 & 1.7 & $\mathrm{~T}$ & Copper & 15 & & & $€ / \mathrm{kg}$ \\
\hline$B$ air gap average & 0.68 & 0.72 & 0.716 & $\mathrm{~T}$ & Iron & 3 & & & $€ / \mathrm{kg}$ \\
\hline B back-iron average & 1.2 & 1.2 & 1.2 & $\mathrm{~T}$ & $\begin{array}{l}\text { Permanent } \\
\text { Magnet }\end{array}$ & 50 & & & $€ / \mathrm{kg}$ \\
\hline \multicolumn{5}{|c|}{ Weight of Active materials used } & \multicolumn{5}{|c|}{ Estimated active material cost of generator } \\
\hline Copper & 10.78 & 7.44 & 10 & ton & Cost of copper & 161.7 & 111.6 & 150 & $\mathrm{k} €$ \\
\hline Iron & 35.68 & 32.69 & 30.6 & ton & Cost of iron & 107.04 & 98.07 & 91.89 & $\mathrm{k} €$ \\
\hline Permanent Magnet & 9.6 & 8.77 & 8.65 & ton & $\begin{array}{l}\text { Cost of } \\
\text { permanent } \\
\text { magnet }\end{array}$ & 480 & 438.5 & 432.5 & $\mathrm{k} €$ \\
\hline Total active mass & 56.6 & 48.9 & 49.28 & ton & Total cost & 748.74 & 648.17 & 674.39 & $\mathrm{k} €$ \\
\hline
\end{tabular}




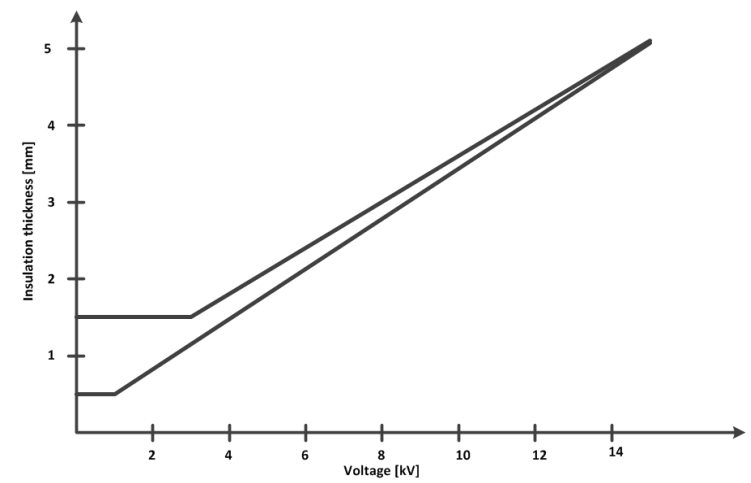

FIGURE 6. Insulation thickness of windings inside a generator slot as a function of RMS rated voltage[7]

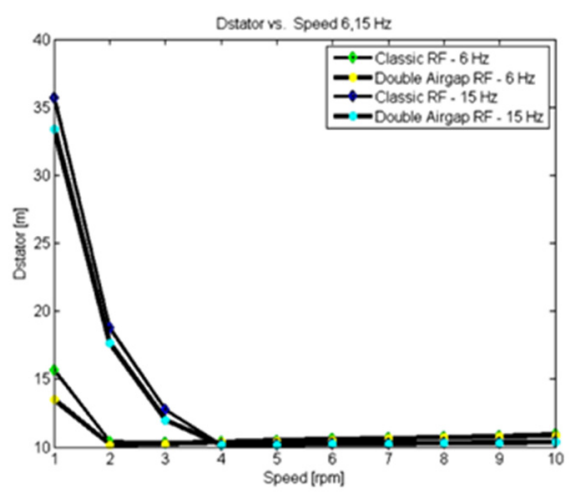

FIGURE 7. Stator outside diameter as a function of speed for two full-load frequencies [9], for a radial flux generator with surface mounted magnets

\section{Rotating Force Wave}

The fractional slot pitch was chosen to minimize cogging torque. This is a parasitic torque arising from the interaction of the rotor poles with the stator slots that is sometimes problematic in machines with permanent magnet excitation. From the finite element analysis, it became clear that the fractional slot winding results in a rotating space force wave with many cycles distributed around the circumference of the generator, Fig. 10. The waves have a force amplitude of some $4.4 \mathrm{GN}$ in the worst case. CAD modelling of the generator indicates that the active materials comprise two, thin-walled cylinders, with a small clearance (air-gap) between them, which if unsupported will be badly distorted by the force wave, causing destructive interference between the rotating components. This force wave must be opposed to prevent catastrophic touchdown between the rotor and stator, thus defining the required stiffness of the structure. To reduce the costs incurred by making a massive structure to support the generator, it will be necessary to compromise the cogging torque and find an optimum design.

\section{Generator Diameter}

It is generally thought that the required full-load torque decides the diameter of an electrical machine, generator or rotor. This is the case, but with the extremely low speeds required by DeepWind, the number of slots required for the winding also affects the diameter, as every slot contains some 'dead' space due to the insulation. The number of slots required may be reduced by selecting a fractional slot winding, and also by reducing the nominal power frequency, as this reduces the number of poles required.

The relationship between shaft speed, frequency and diameter was studied to investigate if this could be used to achieve a smaller diameter of the generator. It is seen from the graph in Fig. 7 that the diameter increases acutely for speeds less than $4 \mathrm{rpm}$ if the rated frequency is $15 \mathrm{~Hz}$, and $2 \mathrm{rpm}$ for $6 \mathrm{~Hz}$. Fig. 7 also shows that little or no advantage is gained by splitting the stator into two portions, one inside the rotor and one outside. It seems that the choice should be for a low frequency, which may be a problem for the power electronics and a high rotational speed, which may be a problem for the turbine. This is an area for future studies.

\section{PROPOSED CONSTRUCTION OF THE GENERATOR}

In view of the low-speed, a fractional slot winding was selected, reducing the cogging torque and the number of slots required. The design tool was used to design the functional electromagnetic parts of the three larger versions, to minimize generator diameter. The diameter was very large, up to $36 \mathrm{~m}$ for $20 \mathrm{MW}$ at $1 \mathrm{rpm},[12,9]$. Different topologies of generator, radial flux, transverse flux, single rotor and double rotor were studied, all with permanent magnet excitation. Cooling was assumed to be by sea water, but it remains to determine the precise configuration of 
this. The surface-mounted permanent magnet, radial flux machines were found to be the best. The number of rotors added to the complication of the construction but made little difference to the mass of material required. The classic radial flux synchronous generator excited by permanent magnets was found to be the simplest construction, with the best performance and was selected. The proposed generation at medium voltage required thick slot insulation, reducing the space available for flux carrying iron in the teeth, making it an advantage to reduce the number of slots as this enabled a reduction in diameter. Many poles and slots are required, see Fig. 8. To minimise the number of poles, slots and thus the diameter, studies were performed on the $5 \mathrm{MW}$ version, at low nominal frequencies, $6 \mathrm{~Hz}$ and $15 \mathrm{~Hz}$. For nominal speeds below $4 \mathrm{rpm}$ the $6 \mathrm{~Hz}$ version required a smaller diameter, see Fig. 7. At nominal speeds above $4 \mathrm{rpm}$, the frequency made no difference to the diameter. Further studies of this phenomenon are needed.

In general, the generator assumes the shape of two concentric thin-walled cylinders, Fig. 9. The minimum diameter found for the $5 \mathrm{MW}$ version at $4 \mathrm{rpm}$ was around $10.2 \mathrm{~m}$. This was not optimised, but required $39.3 \mathrm{ton}$ of $\mathrm{NdFeB}$ magnet, 123 ton of electro-magnet steel and 29 ton of copper. At $10 \mathrm{rpm}$, the required masses of material were considerably reduced, but the wind turbine design team found this speed excessive. In Table 2, the final versions, corresponding to $5.26 \mathrm{rpm}$ may be seen. These are the original version and two optimised versions aiming to minimise the material cost, one using each method, [13. We had most success with the PSO optimization, as not only did it predict the lowest material cost, a reduction to $86.5 \%$ of the original cost, but also the efficiency increased from 0.95 to 0.96 . A disadvantage of this version was that the outer diameter increased from $6.145 \mathrm{~m}$ to $6.561 \mathrm{~m}$.

The arrangement of the fractional slot winding suggests an opportunity to adopt a manufacturing procedure where each coil and its associated iron tooth and core is a single unit, Fig. 8. This could lead to a design where each coil and its tooth could be removed for replacement or maintenance purposes.

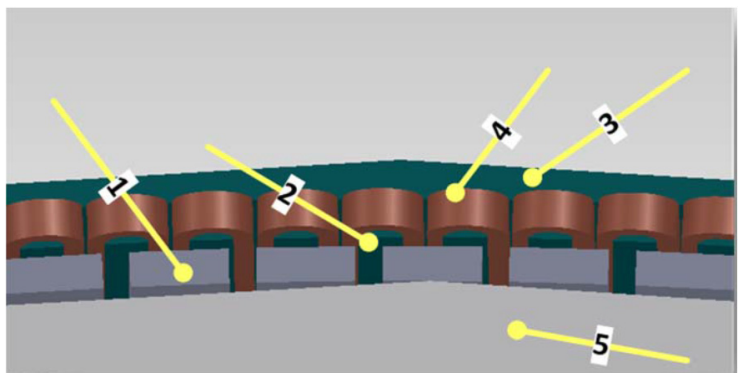

Key:

1- Permanent Magnet

2- 2-Stator Tooth

3- Stator core

4- Coil

5- Rotor Core

FIGURE 8. Generator air-gap view [9]. The coils are fitted in slots and each permanent magnet forms a pole.

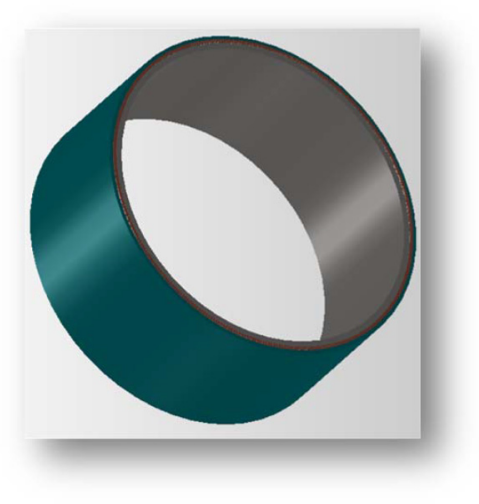

FIGURE 9. The active parts of the generator form two, thin-walled cylinders with relative rotation[9].

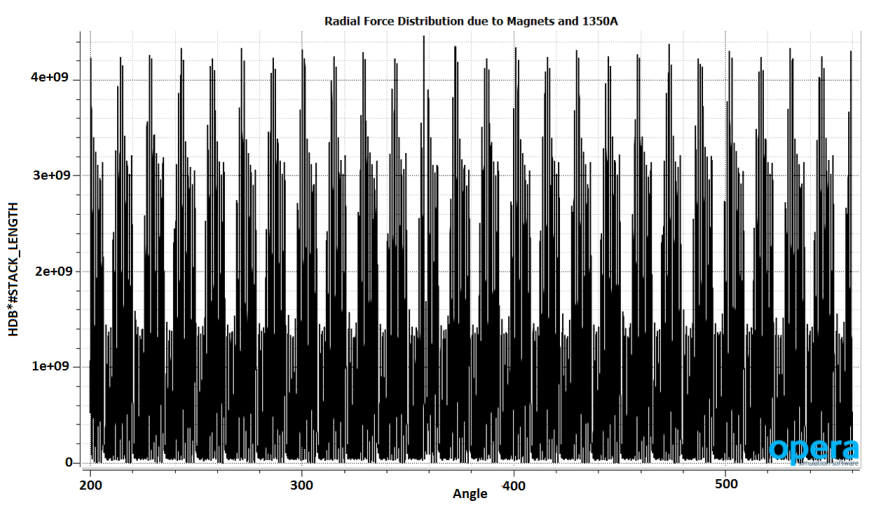

FIGURE 10. Radial force distribution [N] as a function of angle around the air-gap for the $5 \mathrm{MW}$ version with short circuit current (1350 A) flowing. 


\section{GENERATOR PERFORMANCE}

For the $5 \mathrm{MW}$ machine, the electromagnetic efficiency was found to be $96.1 \%$, assuming a winding temperature of $20^{\circ} \mathrm{C}$. As the efficiency given in Table 2 is around $96 \%$, the losses for $5 \mathrm{MW}$ electrical output will be around 200 $\mathrm{kW}$. This must be dissipated in the form of heat without the insulation and the permanent magnets, and the construction elements exceeding their respective allowable temperatures. As the surrounding mass of seawater is very large and may be expected to be around $4{ }^{\circ} \mathrm{C}$ this should provide ample cooling, but the heat is generated inside the generator and must be transmitted to the water. A good way to do this would be to allow the seawater free access inside the generator. Disadvantages of this idea include the conductivity of the seawater, the corrosive nature of the seawater, the friction created by driving it and the possibility of organisms attaching to the moving surfaces.

Mechanically, the generator takes the energy of the VAWT shaft and converts it to electrical energy. To do this the torque of the shaft acts on the stator and the reaction torque is transmitted to the mooring system. This means that the rotor must be mechanically connected to the shaft and the stator must be mechanically connected to the mooring system. Both must have sufficient strength and rigidity to support the operation of the generator under all normal and abnormal conditions without any part sustaining damage. A notable design proposal has been made in [14], where the authors proposed, built and tested a rotor construction that may be suitable for DeepWind generators. The DeepWind team has proposed reinforced concrete to build a stable, cost-effective stator enclosure to transmit not only the torque, but also the forces and moments arising from the VAWT. All details of the generator proposals are freely available in [9].

The generator could develop sufficient torque to provide start, generation and braking under control.

\section{CONCLUSION AND FURTHER WORK}

The radial flux permanent magnet generator was proposed for the DeepWind 500 [kW], 5 [MW] and 20 [MW] versions. This is based on electromagnetic considerations. Many aspects remain to be studied at a later stage and may point to other solutions, including:

- Expected inactive mass: structural elements including generator box and shaft, insulation and support of generator active parts.

- Performance: improved estimation of losses

- Ease of manufacturing, transport and maintenance

- Costs estimated taking into account the cost reduction obtained with series production

The specification of the DeepWind generator and a corresponding design tool were presented. Several versions of the design of the generator for the DeepWind concept were studied using the design tool, finite element analysis and CAD modelling, and proposals were made for the final versions. The optimization programs worked well but the PSO version gave more acceptable results than the GA version and was considerably faster in operation. In addition, areas requiring further study in order to optimize the material usage and structural requirements have been identified. Further studies are needed to determine the best materials for use considering the prevailing conditions at the installation site. The concept should be tested further by building at a suitable site, and operating a small scale system, $500 \mathrm{~kW}$ has been suggested.

\section{ACKNOWLEDGMENTS}

The reported work is a part of the result of Work Package 3 of the DeepWind project which was supported by the European Commission, Grant 256769 FP7 Energy 2010- Future emerging technologies, and by the DeepWind consortium: DTU(DK), AAU(DK), TUDELFT(NL), TUTRENTO(I), DHI(DK), SINTEF(N), MARINTEK(N), MARIN(NL), NREL(USA), STATOIL(N), VESTAS(DK) and NENUPHAR(F). Asger B. Abrahamsen ${ }^{2}$ is acknowledged for support on editing the manuscript. 


\section{REFERENCES}

1. L. Vita, U. S. Paulsen, T. F. Pedersen, "A novel floating offshore wind turbine concept: new developments". In EWEC 2010, Proceedings online European Wind Energy Association (EWEA).

2. U.S. Paulsen, M. Borg, H.Aa. Madsen, T.F. Pedersen, J. Hattel, E. Ritchie, C.S. Ferreira, H. Svendsen, P.A. Berthelsen, C. Smadja,"Outcomes of the DeepWind conceptual design”. In Energy Procedia Vol 80, pp 329341, doi:10.1016/j.egypro.2015.11.437 (2015)

3. E. Ritchie "Development tool for generator design", D3.1, Tech. Report, EU FP7 project, Future Deep Sea Wind Turbine Technologies, Aalborg University(2013)

4. DeepWind http://www.deepwind.eu/ - reports, photos and videos

5. D. R. Verelst, H. A. Madsen, K. A. Kragh and F. Belloni "Detailed Load Analysis of the baseline 5 MW DeepWind Concept". DTU Wind Energy, Technical Report E-0057(2014).

6. C. Galinos, T. Larsen, H.Aa. Madsen, U.S. Paulsen "Vertical axis wind turbine design load cases investigation and comparison with horizontal axis wind turbine". In Energy Procedia 2016 Vol 94, pp 319-328. doi.org/10.1016/j.egypro.2016.09.190.

7. H. Köfler "Losses in Electrical machines". Post- Graduate Course, Faculty of Electrical Engineering Laboratory of Electro Mechanics Helsinki University of Technology Otaniemi, Finland, 1990;ISBN 951-22-0157-7 ISSN 0784-4662 TKK OFFSET.

8. S. Carstensen,X. Mandviwalla, L. Vita, U.S. Paulsen"Lift of a Rotating Circular Cylinder in Unsteady Flows". In The Twenty-second International Offshore and Polar Engineering Conference 2012 Jan 1. International Society of Offshore and Polar Engineers.

9. K.M. Leban, "Design Tool for Direct Drive Wind Turbine Generators: Proposed solutions for direct drive Darrieus generators 20 MW". PhD thesis, Department of Energy Technology, Aalborg University, 2014.

10. A. Argeseanu, F.V.T. Nica, E. Ritchie, and K. Leban "A new geometrical construction using rounded surfaces proposed for the transverse flux machine for direct drive wind turbine." Proceedings of the International Conference on Optimization of Electrical and Electronic Equipment, OPTIM 2014. IEEE Computer Society Press, pp. 415-420 6850953 (2014).

11. A. Zaidi, L. Senn, I. Ortega, P. Radecki, I.E. Szczesny,M. Erkec,E. Ritchie, and K.M. Leban "5MW Direct Drive Wind Turbine Generator Design". In Proceedings of the 20th International Conference on Electrical Machines. Marseille : IEEE Press, 2012. p. 1140 - 1145.

12. K.M. Leban, E. Ritchie, A. Argeseanu "Design Tool for 5-20 MW Direct Drive Generators."

13. F.V.T. Nica, K.M. Leban, and E. Ritchie "Direct drive TFPM wind generator analytical design optimised for minimum active mass usage". In Proceedings of the 8th International Symposium on Advanced Topics in Electrical Engineering, ATEE 2013. IEEE Press( 2013)

14. Y. Alexandrova Y, R. Semken, and J. Pyrhönen "Permanent Magnet Synchronous Generator Design Solution for Large Direct-Drive Wind Turbines". In International Review of Electrical Engineering 2013 